
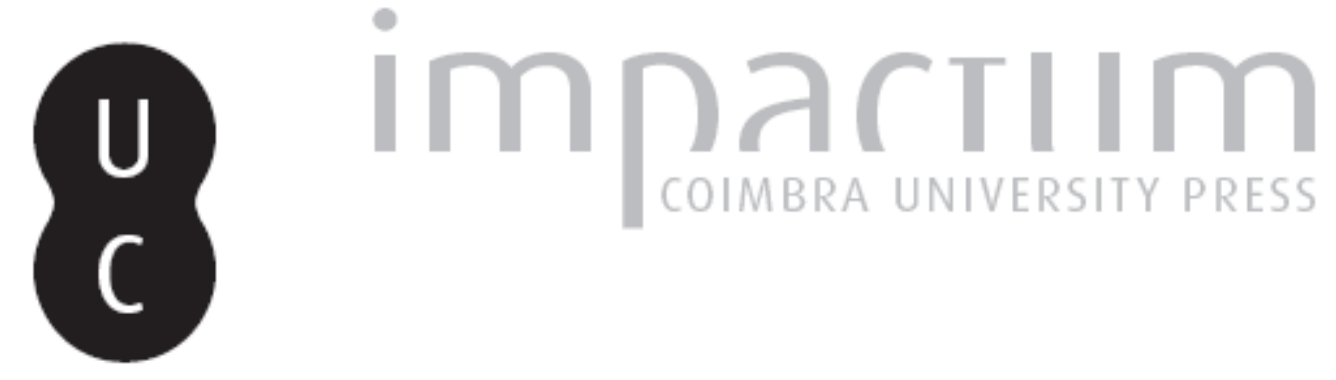

\title{
[Recensão a] Bernardim Ribeiro, Storia di una giovane fanciulla, traduzione dal portoghese Alfonso Bruno Parisini
}

\author{
Autor(es): $\quad$ Almeida, Isabel
}

Publicado por: Imprensa da Universidade de Coimbra

URL persistente:

URI:http://hdl.handle.net/10316.2/42399

DOI:

DOI:https://doi.org/10.14195/0870-8584_10_12

Accessed : $\quad$ 26-Apr-2023 16:13:42

A navegação consulta e descarregamento dos títulos inseridos nas Bibliotecas Digitais UC Digitalis, UC Pombalina e UC Impactum, pressupõem a aceitação plena e sem reservas dos Termos e Condições de Uso destas Bibliotecas Digitais, disponíveis em https://digitalis.uc.pt/pt-pt/termos.

Conforme exposto nos referidos Termos e Condições de Uso, o descarregamento de títulos de acesso restrito requer uma licença válida de autorização devendo o utilizador aceder ao(s) documento(s) a partir de um endereço de IP da instituição detentora da supramencionada licença.

Ao utilizador é apenas permitido o descarregamento para uso pessoal, pelo que o emprego do(s) título(s) descarregado(s) para outro fim, designadamente comercial, carece de autorização do respetivo autor ou editor da obra.

Na medida em que todas as obras da UC Digitalis se encontram protegidas pelo Código do Direito de Autor e Direitos Conexos e demais legislação aplicável, toda a cópia, parcial ou total, deste documento, nos casos em que é legalmente admitida, deverá conter ou fazer-se acompanhar por este aviso.

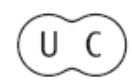




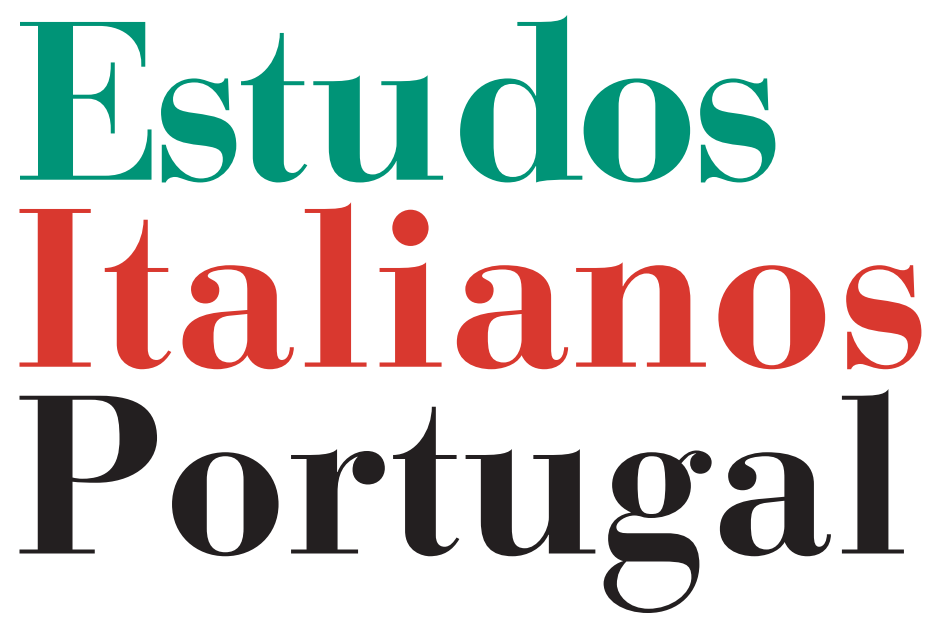

Instituto

Italiano

de Cultura

de Lisboa

Nova Série

$\mathrm{N}^{\mathbf{0}} 10$

2015 
brio - quasi ritrosia da religiosità "orientale" - politico e ideologico, lontano da ogni enfasi rivoluzionaria: «Non pretendiamo di imporre delle opinioni; vogliamo semplicemente esporre le nostre: non chiediamo adesione, ma solo dibattito. $\mathrm{Ci}$ inseriamo placidamente nel campo delle idee: ci ripugnano le rivoluzioni violente e, proprio perché ci ripugnano, ci appelliamo al dibattito sereno» (p. 87).

Leggere oggi in italiano le Cause della decadenza dei popoli peninsulari negli ultimi tre secoli di Antero de Quental significa fare una volta ancora i conti con un classico del pensiero ottocentesco portoghese che forse meno per la sua radicalità interpretativa (le tre cause della decadenza iberica - religiosa, politica e economica - avrebbero avuto tre conseguenze devastanti sul mancato appuntamento con la Modernità europea da parte della penisola) che per il gesto ideologico di «agire sul destino del paese» ha rappresentato il più formidabile tentativo di decifrare ma anche - non senza una certa hybris di emendare il tempo portoghese. VINCENZO RUSSO

Bernardim Ribeiro, Storia di una giovane fanciulla, traduzione dal portoghese Alfonso Bruno
Parisini, Siena, Vittoria Iguazu Editore, 2014, pp. 119.

Quatrocentos e sessenta anos depois da sua primeira impressão (Ferrara, 1554), a História de Menina e Moça, de Bernardim Ribeiro, voltou a ser dada à estampa em Itália, agora traduzida por Alfonso Bruno Parisini.

O livro, Storia di una giovane fanciulla, começa por oferecer um texto de apresentação - "Menina e Moça: un enigma che perdura nei secoli" - concebido por Valeria Tocco, professora da Universidade de Pisa e investigadora que à Literatura e à Cultura portuguesas desde sempre se dedicou. Questões intrigantes e linhas de leitura possíveis são traçadas com clareza. Valeria Tocco recorda a falta de notícias sobre o autor, Bernardim Ribeiro, nascido por finais do século XV; chama a atenção para a complexidade que o hibridismo da História de Menina e Moça (misto de narrativa sentimental, ficção cavaleiresca e canto bucólico) suscita; e destaca hipóteses interpretativas, admitindo que, por deliberação do seu criador ou por efeito das circunstâncias históricas, a obra - enquanto representação de um mundo triste, impregnado de 
simbolismo e protagonizado por figuras às quais a fortuna impõe a experiência da perda, do exílio ou até da ocultação da verdadeira identidade - se prestaria a um entendimento em clave judaizante. Adverte Valeria Tocco: o facto de, em 1554, História de Menina e Moça ter saído dos prelos do sefardita Abraão Usque, cujo labor se dirigia a um público hebraico forçado a dolorosa diáspora, torna plausível esta ideia.

Ao cuidado de enquadrar a obra e de salientar suas características e seus mistérios, teria sido interessante juntar um preâmbulo assinado pelo próprio Alfonso Bruno Parisini. O texto quinhentista é tão belo quanto difícil, e difíceis são as escolhas que a tradução implica. Por isso importaria que Alfonso Bruno Parisini desenvolvesse e partilhasse uma reflexão crítica, quer para reconhecer problemas quer para justificar as soluçôes adoptadas.

Escassa é a nota que informa sobre a matriz desta versão italiana (p. 14), e sobretudo nunca se explica por que motivo depositou o tradutor plena confiança na lição "curata da" José Hermano Saraiva e Maria de Lourdes Saraiva "per i tipi della casa editrice Europa/
América" (Bernardim Ribeiro, Menina e Moça. 4a ed. anotada. Edição do texto, actualização e comentário explicativo de Maria de Lourdes Saraiva, Mem Martins, Publicações Europa/América, 1996). Um olhar sobre as composições poéticas disseminadas na História de Menina e Moça chega para perceber que o texto de 1554 não é escrupulosamente mantido por aqueles editores, ao contrário do que Alfonso Bruno Parisini parece crer sem reservas. De resto, na transcrição em geral detectam-se erros flagrantes, como "E ela ouve-o por bem” (p. 58), em vez de "E ela houve-o por bem" (i.e., concordou) - erros que, ao não serem filtrados, geram novos equívocos ("Lei lo ascoltò con attenzione" p. 40). Estando disponível, desde 2002, a reprodução fac-similada da edição de Ferrara, que, com estudo preambular, foi levada a cabo por José Vitorino de Pina Martins, esperar-se-ia maior rigor na eleição da base de trabalho.

Decerto, ninguém estranhará o desejo de tornar acessível o texto, desde logo pelo recorte de capítulos e pela abertura de parágrafos que a editio princeps ou não inclui ou só em raros lugares comporta. Mas se ao proceder assim Alfonso 
Bruno Parisini segue o modelo definido por José Hermano Saraiva e Maria de Lourdes Saraiva, já dele diverge quando elide o que na prosa de Bernardim é a intensa ligação do discurso, que corre num fluxo longo, articulado por elementos conectores como "mas", "antes que", "que". Não são pormenores despiciendos. Repare-se na diferença que o seu desaparecimento provoca:

"Mas em isto, como em as outras cousas, também me enganei. Que agora há já dois anos que estou aqui, e não sei ainda tão somente determinar para quando me aguarda a derradeira hora." (p. 25) "Ma anche in questo, come in tutto il resto, mi sono sbagliata. Sono già passati due anni da quando sono giunta qui, e ancora non so quando mi aspetta l'ultima ora." (p. 18)

Em toda a tradução espreita uma belle infidèle, mas os desvios relativamente à letra original devem ter sua pertinência. Por que razão Alfonso Bruno Parisini prefere, à busca de meticulosas correspondências lexicais e semânticas, a liberdade de traduzir "nojo do mar" por "fatiche del viaggio" (p. 34), "dobando" por "tessendo" (p. 28), “vingança” por "rimedio" (p. 38), “minhas mágoas" por "il mio dolore” (p. 20), etc.? Por que razão apaga qualificativos, escrevendo "notte" (p. 21) em vez de "noites caladas", "pastor" (p. 58) em vez de "velho pastor", etc.? Do mesmo modo, haveria que dizer com que critério introduz variações inexistentes no texto de Bernardim, como sucede no tratamento do adjectivo "rico", transformado também em "lussuos[o]" (p. 41) e "prezioso" (p. 49).

Será esta atitude, porventura apressada ou menos ponderada, a causa de um ou outro desencontro. Veja-se, por exemplo:

"Deteve Bimarder o passo, espantado daquilo que ainda até então cuidava ele que o não sabia ninguém." (p. 80)

É manifesta a ênfase no espanto da personagem perante a interpelação vinda de uma "sombra" afinal senhora dos seus mais íntimos segredos. Mas "aquilo que ainda até então cuidava ele que o não sabia ninguém" é mais do que a mudança de nome do cavaleiro; é tudo o que cabe na frase imediatamente anterior ("Está quedo, Bimarder chamando-o assim pelo seu nome lhe disse a sombra -, que ainda 
agora foste vencido por uma donzela chorando!...”), e que a versão italiana acaba por não contemplar: "Bimarder arrestò il passo, spaventato; credeva che nessuno conoscesse ancora il suo nome." (p. 55)

\section{Coteje-se, por último:}

"Isto dizia ela, porque era costume mui guardado naquela terra, e ficara doutro tempo, sob grandes penas, proibido, não se pôr mulher nenhuma em cabelo senão por seu marido." (p. 57)

"Diceva questo perché strapparsi i capelli era un'usanza molto antica di quella terra, ma era proibito da molto tempo, con grandi pene, a ogni donna, a meno che non lo facesse per il proprio marito." (p. 39)

"Pôr-se em cabelo" (mostrar a cabeça nua, sem qualquer véu ou toucado) não é sinónimo de "strapparsi i capelli". Para evitar tais confusões, basta uma análise mais paciente e mais exigente $\mathrm{da}$ obra de Bernardim Ribeiro.

O leitor que comparar o texto original com a tradução de Alfonso Bruno Parisini notará discrepâncias como as que procurámos, a título de exemplo, assinalar. Não deixará de apreciar, porém, o trabalho realizado e o equilíbrio ami- úde conseguido. Cumpre louvar a coragem subjacente à preparação da Storia di una giovane fanciulla e agradecer o contributo dado à difusão de uma extraordinária obra portuguesa do tempo do Renascimento.

ISABEL ALMEIDA

José de Almada Negreiros, Prose d'avanguardia, a cura di Valeria Tocco, Perugia, Edizioni dell'Urogallo, 2014, pp. 191.

José de Almada Negreiros, Nome di battaglia, trad. di Andrea Ragusa, Perugia, Edizioni dell'Urogallo, 2014, pp. $184+$ n.n.

Nel passato 2014, un piccolo editore di Perugia, le Edizioni dell'Urogallo, ha dato alle stampe due volumi eleganti su cui spicca la firma dei uno dei più importanti protagonisti del Modernismo portoghese: José de Almada Negreiros. Entrambe le pubblicazioni sono il risultato del lavoro di un'équipe di studiosi e traduttori italiani, coordinata da Valeria Tocco (Università di Pisa), che ha portato alla realizzazione del congresso internazionale Almada Negreiros: un trait d'union tra arti e culture (Pisa 10-12 giugno 2015), e della mostra Almada Negreiros, artista prismati- 